Article

\title{
The Eukaryotic Elongation Factor 1 Alpha (eEF1 $\alpha$ ) from the Parasite Leishmania infantum Is Modified with the Immunomodulatory Substituent Phosphorylcholine (PC)
}

\author{
Thomas Timm ${ }^{1,+}$, Giada Annoscia ${ }^{2,+}$, Jochen Klein ${ }^{3}$ and Günter Lochnit ${ }^{1, *}$ \\ 1 Protein Analytics, Institute of Biochemistry, Faculty of Medicine, Justus-Liebig-University Giessen, \\ Friedrichstrasse 24, 35392 Giessen, Germany; thomas.timm@biochemie.med.uni-giessen.de \\ 2 Department of Veterinary Medicine, University of Bari, Str. prov. per Casamassima km 3, Valenzano, \\ 70010 Bari, Italy; annoscia.giada@gmail.com \\ 3 Department of Pharmacology, Goethe University College of Pharmacy, 60438 Frankfurt, Germany; \\ klein@em.uni-frankfurt.de \\ * Correspondence: Guenter.Lochnit@biochemie.med.uni-giessen.de; Tel.: +49-641-994-7462; \\ Fax: +49-641-994-7489 \\ + These authors contributed equally to this manuscript.
}

Received: 27 October 2017; Accepted: 24 November 2017; Published: 29 November 2017

\begin{abstract}
Proteins and glycolipids have been found to be decorated with phosphorylcholine (PC) both in protozoa and nematodes that parasitize humans and animals. PC epitopes can provoke various effects on immune cells leading to an immunomodulation of the host's immune system that allows long-term persistence of the parasites. So far, only a limited number of PC-modified proteins, mainly from nematodes, have been identified. Infections caused by Leishmania spp. (e.g., L. infantum in southern Europe) affect about 12 million people worldwide and are characterized by a wide spectrum of clinical forms in humans, ranging from cutaneous to fatal visceral leishmaniasis. To establish and maintain the infection, these protozoa are dependent on the secretion of effector molecules into the host for modulating their immune system. In this project, we analyzed the PC modification of L. infantum promastigotes by 2D-gel based proteomics. Western blot analysis with the PC-specific antibody TEPC-15 revealed one PC-substituted protein in this organism, identified as eEF1 $\alpha$. We could demonstrate that the binding of eEF1 $\alpha$ to one of its downstream effectors is dependent on its PC-modification. In this study we provide evidence that in this parasite the modification of eEF1 $\alpha$ with PC may be essential for its function as an important virulence factor.
\end{abstract}

Keywords: Leishmania infantum; promastigote; proteomics; phosphorylcholine; immunomodulation; immunofluorescence

\section{Introduction}

Leishmaniasis, a vector-borne worldwide-distributed parasitic disease, is caused by dimorphic protozoan flagellates of the genus Leishmania. This organism alternates between two different stages: the promastigote lives extracellular in its vector, the phlebotomine sandfly (Diptera, Psychodidae), and the amastigote resides within the phagolysosome of mononuclear macrophages of mammalian hosts. The disease is characterized by diversity and complexity, presenting a wide spectrum of clinical forms in humans, ranging from cutaneous leishmaniasis (CL) to fatal visceral leishmaniasis (VL) [1,2].

Recent studies have reported the diffusion of new "hot spots" of canine leishmaniosis in previously non-endemic areas of the northern United States and some provinces of southern Canada and northern Europe [3-5]. Leishmaniosis seems to spread because of a combination of 
factors: environmental/climatic changes, factors related to the immune status of the host and drug resistance [6,7]. Therefore, over the last decades, considerable efforts have been directed towards the research into new proteinacious targets for the development of an effective therapy against human VL.

Phosphorylcholine (PC, Figure 1) has been recognized as a common antigenic determinant in many important disease-causing parasites, such as, gastrointestinal and filarial nematodes [8] but also in protozoa like Trypanosoma and Leishmania [9].

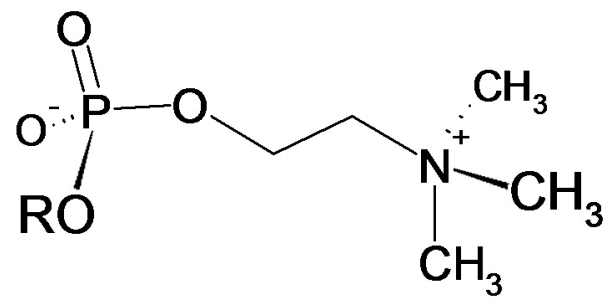

Figure 1. Structure of the phosphocholine functionality with $\mathrm{R}$ being an $\mathrm{N}$-glycan or the sidechaine of an amino acid.

PC-bearing antigens have been found to possess immunomodulatory capacity and to interfere with key proliferative signaling pathways in B- and T-cells, dendritic cell maturation and mast cell degranulation, thus facilitating the survival of parasites in their hosts [8,10-17]. Therefore, these effects could contribute to the observed modulated cytokine levels and impairment of lymphocyte proliferation. Detailed data on the different types of PC-carrying biomolecules as well as their biosynthesis, however, are limited and have only been reported in the last few years in nematodes [8,18-21].

Structural analyses of nematode-derived molecules with PC epitopes focused, so far, on glycolipids and glycoprotein glycans. It could be shown that glycosphingolipids of the pig parasitic nematode, Ascaris suum, are characterized by the presence of a phosphodiester-bound PC-substituent which has been assigned to C- 6 of the central $N$-acetylglucosamine (GlcNAc) residue of an arthro-series carbohydrate core [22]. Furthermore, some glycolipid species were found to carry phosphorylethanolamine linked to C-6 of an adjacent mannose residue in addition to PC [23,24]. Comparable glycosphingolipids have been verified in different nematodes, including Nippostrongylus brasiliensis [25], Litomosoides sigmodontis [26,27], Onchocerca volvulus and Setaria digitata [27], indicating that arthro-series glycosphingolipids carrying, in part, PC substituents represent highly conserved glycolipid markers within the nematode phylum. A biosynthetic route homologous to A. suum glycosphingolipids was also confirmed for the free-living nematode Caenorhabditis elegans $[23,28,29]$.

Analogous analyses of the PC-substituted glycoprotein ES-62, an excretory/secretory (ES) product of Acanthocheilonema viteae, indicated that the zwitterionic substituent is linked via $N$-glycans to the polypeptide backbone [30,31]. Mass spectrometric analysis of the respective $N$-linked glycans revealed the presence of trimannosyl $\mathrm{N}$-glycan variants, carrying between one and four terminal GlcNAc residues [32]. Only this type of glycans was found to be substituted with PC-moieties which could be again assigned to C- 6 of terminal GlcNAc residues [33,34]. Comparative studies of $\mathrm{N}$-glycans present in extracts of $A$. viteae, Onchocerca gibsoni and O. volvulus confirmed a high conservation of such PC-substituted $\mathrm{N}$-glycans within filarial parasites [35]. For C. elegans, two types of PC-substituted $\mathrm{N}$-glycans have been reported so far: (1) a pentamannosyl-core structure carrying up to three PC-residues [36] and (2) trimannosyl-core species elongated by GlcNAc residues substituted at C-6 with PC [33]. Furthermore, combinations of both types of structural motifs [19] as well as the occurrence of extended glycan structures with composition of $P C h o_{1-2} \mathrm{dHex}_{0-2} \mathrm{Hex}_{3-5} \mathrm{HexNAc}_{3-7}$ have been reported [18]. For A. suum hybrid-type bi- and triantennary $\mathrm{N}$-glycans substituted with PC have been described [21]. 
PC-modified proteins were also detected in different developmental stages of the malarial blood parasite Plasmodium falciparum [37]. Fourteen putative proteins carrying the PC modification were identified, among them, proteins that are located on the surface of the parasite, or are involved in metabolism. Erythrocyte membrane protein 1 (EMP1, a member of the var gene family), together with the heat shock protein 70 (HSP-70), was detected in every P. falciparum stage of the erythrocyte pathway. In P. falciparum, var genes encode adhesive proteins that are transported to the surface of infected erythrocytes, thereby acting as major virulence determinants for immune evasion [38,39]. There is increasing evidence that HSP-70 could play an important role in the life cycle of P. falciparum both as a chaperone and as immunogen [40]. In the merezoite-stage, only one surface protein (EMP1, P154varH), was detected.

The eukaryotic elongation factor- $1 \alpha(\mathrm{eEF} 1 \alpha)$ is an enzyme that catalyzes the GTP-dependent binding of aminoacyl-tRNA to the A-site of ribosomes during protein synthesis and is involved in the capture of deacylated tRNA [41,42]. Furthermore, eEF1 $\alpha$ was found to serve as a central hub in protein networks with hundreds of interacting partners [43,44]. Leishmania eEF1 $\alpha$ was found to bind and activate the Src-homology 2 domain containing protein tyrosine phosphatase-1 (SHP-1), a protein known to be involved in the macrophage inactivation pathogenesis of leishmaniasis [41]. Additionally, eEF1 $\alpha$ was found in Leishmania exosomes and identified as an important factor for immunosuppression and priming host cells for Leishmania invasion [41,45].

In this study, we identified eEF1 $\alpha$ as the only PC-positive protein found in Leishmania infantum MON-1 by a 2D-gel proteomic approach. Furthermore, we confirmed the presence of PC modifications by quantitative determination of its choline content. Additionally, we localized the PC epitopes within procyclic and stationary phase promastigotes by confocal microscopy. Finally, we were able to demonstrate that the interaction of L. infantum EF1 $\alpha$ and human SHP-1 is dependent on the PC modification of EF1 $\alpha$.

\section{Materials and Methods}

\subsection{Cultivation of Leishmania infantum Promastigotes}

L. infantum zymodeme MON-1 promastigotes were cultured in Tobie-Evans modified medium at $24{ }^{\circ} \mathrm{C}$ [46]. Promastigotes at day 3 or 10 of culture were used. The liquid phases were centrifuged at $1000 \times \mathrm{g}$ for $5 \mathrm{~min}$ at $4{ }^{\circ} \mathrm{C}$. Supernatant was then discarded and the pellet was resuspended in phosphate buffered saline (PBS) pH 7.2, and washed 3 times by centrifugation at $1000 \times g$ for $10 \mathrm{~min}$.

\subsection{Immunofluorescence}

L. infantum promastigotes were washed twice in PBS before fixation in $200 \mu \mathrm{L}$ of $1 \%$ formaldehyde in PBS for $30 \mathrm{~min}$ at room temperature (RT). After a PBS wash, the cells were permeabilized by resuspension in $200 \mu \mathrm{L}$ of $0.1 \%$ Triton X-100 in PBS for 10 min. Following an additional PBS wash, the cells were resuspended in $200 \mu \mathrm{L}$ of $0.1 \mathrm{M}$ glycine in PBS and incubated for a further $10 \mathrm{~min}$ at RT before being washed in PBS. Glass slides were washed with $70 \%$ ethanol and coated with a $0.01 \%$ solution of poly-L-lysine (0.1\% stock; Sigma Alrich, Taufkirchen, Germany), and the fixed, permeabilized cells were then left to sediment and adhere to the surfaces of these polylysine-coated slides for $15 \mathrm{~min}$ at RT.

Monoclonal mouse TEPC-15 (Sigma Aldrich, Taufkirchen, Germany) diluted 1:1000 in TB buffer $(0.1 \%(v / v)$ Triton X-100, 0.1\% $(w / v)$ bovine serum albumin (BSA) in PBS), was added to the slide and incubated with the cells overnight at $4{ }^{\circ} \mathrm{C}$. After a 10-mL PBS wash, cells were incubated in the dark for $1 \mathrm{~h}$ at RT with FITC-conjugated secondary antibodies (LifeTechnologies, Darmstadt, Germany) diluted 1:500 in TB buffer. Unbound secondary antibody was washed away with $1.5 \mathrm{~mL}$ PBS (3-times $0.5 \mathrm{~mL}$ ).

The cells were then covered with $10 \mu \mathrm{L}$ of Vectashield mounting medium with DAPI for staining of the cellular DNA (Vector Laboratories, Burlingame, CA, USA). 
Preparations were examined with a Zeiss LSM 710 confocal microscope using a $488 \mathrm{~nm}$ laser for FITC and a $405 \mathrm{~nm}$ laser for DAPI. The instrument control and image analysis were done with the software ZEN (version 2012, blue edition; Zeiss, Wetzlar, Germany).

\subsection{Protein Isolation}

Parasites were prepared as described in section "Cultivation of Leishmania infantum promastigotes". Approximately $10 \mathrm{mg}$ of pelleted promastigotes were homogenized in $30 \mu \mathrm{L} 0.2 \%(w / v)$ sodium dodecylsulfate (SDS; Roth, Karlsruhe, Germany) and boiled for $5 \mathrm{~min}$ at $95{ }^{\circ} \mathrm{C}$. After cooling on ice, the sample was extracted with $370 \mu \mathrm{L}$ lysis buffer consisting of $6 \mathrm{M}$ urea (Sigma, Taufkirchen, Germany), $2 \mathrm{M}$ thiourea (Sigma, Taufkirchen, Germany), 1\% Triton X-100 (Fluka, Selze, Germany), 65 mM dithiothreitol (DTT; Fluka, Selze, Germany), 0.5\% IPG-buffer pH 3-10 (GE Healthcare, Freiburg, Germany), $0.1 \mathrm{mM}$ phenylmethylsulfonylfluoride (PMSF; Sigma, Taufkirchen, Germany), and Protease Inhibitor Cocktail for general use (Sigma Alrich, Taufkirchen, Germany). Sample homogenization was done by four pulses of $30 \mathrm{~s}$ in a bullet blender using $1.4 \mathrm{~mm}$ stainless steel beads (Next Advance, New York, NY, USA) with intermediate cooling on ice and centrifugation $(20,000 \times g$, $1 \mathrm{~h}$ at $4{ }^{\circ} \mathrm{C}$ ). To remove lipid contaminants and SDS proteins were precipitated with chloroform $/ \mathrm{methanol}$ $(1: 4$ by $v / v)$. For isoelectric focusing, the protein pellet was dissolved in $100 \mu \mathrm{L}$ lysis buffer containing 4\% 3-3'-(Cholamidopropyl)-3,3-dimethylammoniumpropylsulfat (CHAPS; Roth, Karlsruhe, Germany) instead of Triton X-100 and 2\% IPG-buffer pH 3-10 [47].

\subsection{Two-Dimensional Gel Electrophoresis and Detection of PC-Modified Proteins}

Two-dimensional separation, Western blotting of proteins and detection of PC-modified proteins was performed as described in [47]. For preparative gels $0.4-0.5 \mathrm{mg}$, and for Western blot analysis $25 \mu \mathrm{g}$ of the extracted protein were loaded.

eEF1 $\alpha$ was detected by the specific antibody PA5-17213 (Thermo Scientific, Dreieich, Germany, 1:2000 dilution) with horseradish peroxidase conjugated anti-rabbit Ig (DakoCytomation, Glostrup, Denmark, 1:2000) as secondary antibody. Proteins recognized by the antibodies were visualized by enhanced chemiluminescence using the ECL SuperSignal kit (GE Healthcare, Solingen, Germany). The corresponding protein spots were excised from preparative gels with the ExQuest ${ }^{\mathrm{TM}}$ Spot Cutter (Bio-Rad, Munich, Germany) and transferred into 96-well plates (Greiner Bio-One, Frickenhausen, Germany).

2.5. Tryptic in-Gel Digestion of Proteins, Matrix-Assisted Laser-Desorption Ionization Time-of-Flight Mass Spectrometry (MALDI-TOFMS) and Database Search

Performed as described in [47].

\subsection{Choline Quantification}

For the quantitation of choline-substitution of eEF1 $\alpha, 400 \mu \mathrm{g}$ of total protein from L. infantum were separated on a 2D-gel as described above and stained with Flamingo ${ }^{\mathrm{TM}}$ according to the instructions of the manufacturer (BioRad, München, Germany). The absolute amount of eEF1 $\alpha$ was determined by densitometric analysis using Quantity One 4.6.2 (Bio-Rad, Munich, Germany) using lysozyme (14.3 kDa, $5 \mu \mathrm{g}), \beta$-lactoglobulin $(18.4 \mathrm{kDa}, 3 \mu \mathrm{g})$, aldolase (36 kDa, $2 \mu \mathrm{g})$, and bovine serum albumin (66 kDa, $1 \mu \mathrm{g}$; all from Sigma Aldrich, Taufkirchen, Germany) as standards (see results). The spots containing 1.9 and 2.1 respectively $\mu \mathrm{g}$ of EF1 $\alpha$ were cut from the gels and tryptic digestion was performed as described above. PC residues were removed from the peptides by cleavage of the phosphodiester bonds with hydrogen fluoride: one sixth $(6.26 / 7.25$ pmol) of the tryptic digest of eEF1 $\alpha$ was lyophilized, dissolved in $50 \mu \mathrm{L}$ of hydrofluoric acid (48\%, Merck, Darmstadt, Germany) and incubated on ice overnight. The sample was dried under a stream of nitrogen, dissolved in $500 \mu \mathrm{L}$ of water and lyophilized. Choline was measured by HPLC according to published methods [48]. 


\subsection{Co-Purification of Leishmania EF1 $\alpha$ with Human SHP-1}

Approximately $50 \mathrm{mg}$ of pelleted promastigotes were extracted with $1 \mathrm{ml}$ RIPA buffer $(25 \mathrm{mM}$ TRIS-HCl pH 7.6, $150 \mathrm{mM} \mathrm{NaCl}$, 1\% NP40, 1\% sodium deoxycholate, 0.1\% SDS), half of the extract was supplemented either with $2 \mu \mathrm{g}$ of GST-SHP-1 (Jena Bioscience, Jena, Germany) alone or in presence of phosphorylcholine ( $5 \mathrm{mM}$ final concentration; Sigma Aldrich, Taufkirchen, Germany). To get rid of residual glutathione from the preparation of GST-SHP-1, the buffer was exchanged three times by ultrafiltration (10 kDa cutoff; Amicon, Darmstadt, Germany). After an incubation on ice for three hours, the solutions were separately passed two times through $50 \mu \mathrm{L}$ glutathione agarose (Jena Bioscience, Jena, Germany), pre-incubated with RIPA or RIPA/PC respectively. Proteins were then eluted with $80 \mu \mathrm{L}$ of twofold concentrated Laemmli sample buffer and subjected to SDS-PAGE. Western blotting and detection was performed as described above using 3\% BSA in TBS-T instead of Roti-Block.

\subsection{Staining of Proteins on Western Blot Membranes}

To visualize all the proteins transferred to the PVDF membranes these were incubated with black Fount India Ink (Pelikan, Hannover, Germany; diluted 1:1000 in PBS-T) for at least five hours, washed five times with pure water and dried.

\section{Results}

\subsection{D-Gelelectrophoresis and Western Blot Analyses}

The L. infantum promastigote protein extract was separated by 2D-gel electrophoresis and proteins were visualized by Flamingo staining (see Figure 2A). A weak blockage in the iso-electric focusing (IEF) could be observed in the basic region of the gel probably due to nucleic acids in the sample; however, protein spots were clearly resolved even at the very basic region of the gel.

PC-epitopes were detected by western blotting using the PC-specific antibody TEPC-15. Only a single ellipsoid spot was found after ECL (see Figure 2B) even after longer exposure (ten times) of the film (Figure 2C). The ellipsoid form of the spot gave first indication for the presence of several isoforms / post-translational modifications of the protein(s) beyond the spot.

The PC-positive spot from the western blot could be clearly matched to a protein spot on the Flamingo stained gel with an apparent molecular weight of approx. $50 \mathrm{kDa}$ and a pI of approximately 9.5.

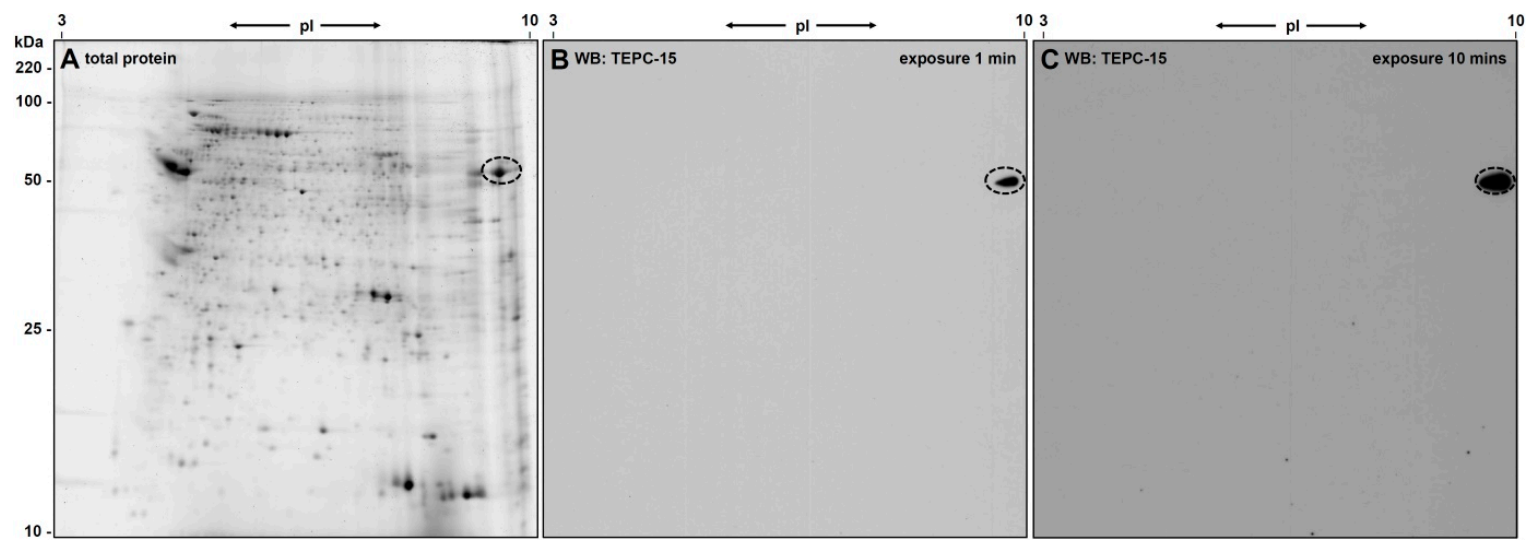

Figure 2. 2D-Gel electrophoretic separation of L. infantum proteins. (A) Gel stained with Flamingo for total protein visualization and $(\mathbf{B}, \mathbf{C})$ ECLs of a Western blot probed with the PC-specific antibody TEPC15. One spot is detected as being PC-modified, even if the film is overexposed: image (C) is exposed for $10 \mathrm{~min}$, although the spot is already visible after $1 \mathrm{~min}(\mathbf{B})$. The corresponding spot in (A) is labelled with a circle. 


\subsection{Identification of eEF1alpha}

For protein identification, the complete PC-positive spot was isolated from the Flamingo-stained gel, digested with trypsin and subjected to MALDI-TOF-MS peptide fingerprint analysis. The resulting peptide mass list from the MS spectra acquired (see Figure 3A) was used for a database search using the MASCOT search engine and an in house installed Leishmaniinae database extracted from Uniprot.

The database search presented only one protein hit (accession no A4HX73) with statistical significance $(p<0.05)$ and with a MOWSE score of 187 , the elongation factor 1 alpha $(\mathrm{eEF} 1 \alpha$; see Figure 3B). The matched peptides (highlighted in red in Figure 3C) covered 58\% of the amino acid sequence with an intensity coverage of $64 \%$. A re-search with unmatched masses from the initial search yielded no significant identification, excluding the presence of a second protein in that particular spot. A re-search including PC as an optional modification on serine, threonine, tyrosine, lysine and cysteine residues did not lead to an identification of PC-modified peptides. From the amino acid sequence of the database entry a molecular weight of $49.5 \mathrm{kDa}$ and a pI of 9.03 could be calculated. The observed molecular weight ( $50 \mathrm{kDa}$ ) fits well to the theoretical value whereas the apparent $\mathrm{pI}$ (approx. 9.5) is a slightly more basic than expected.

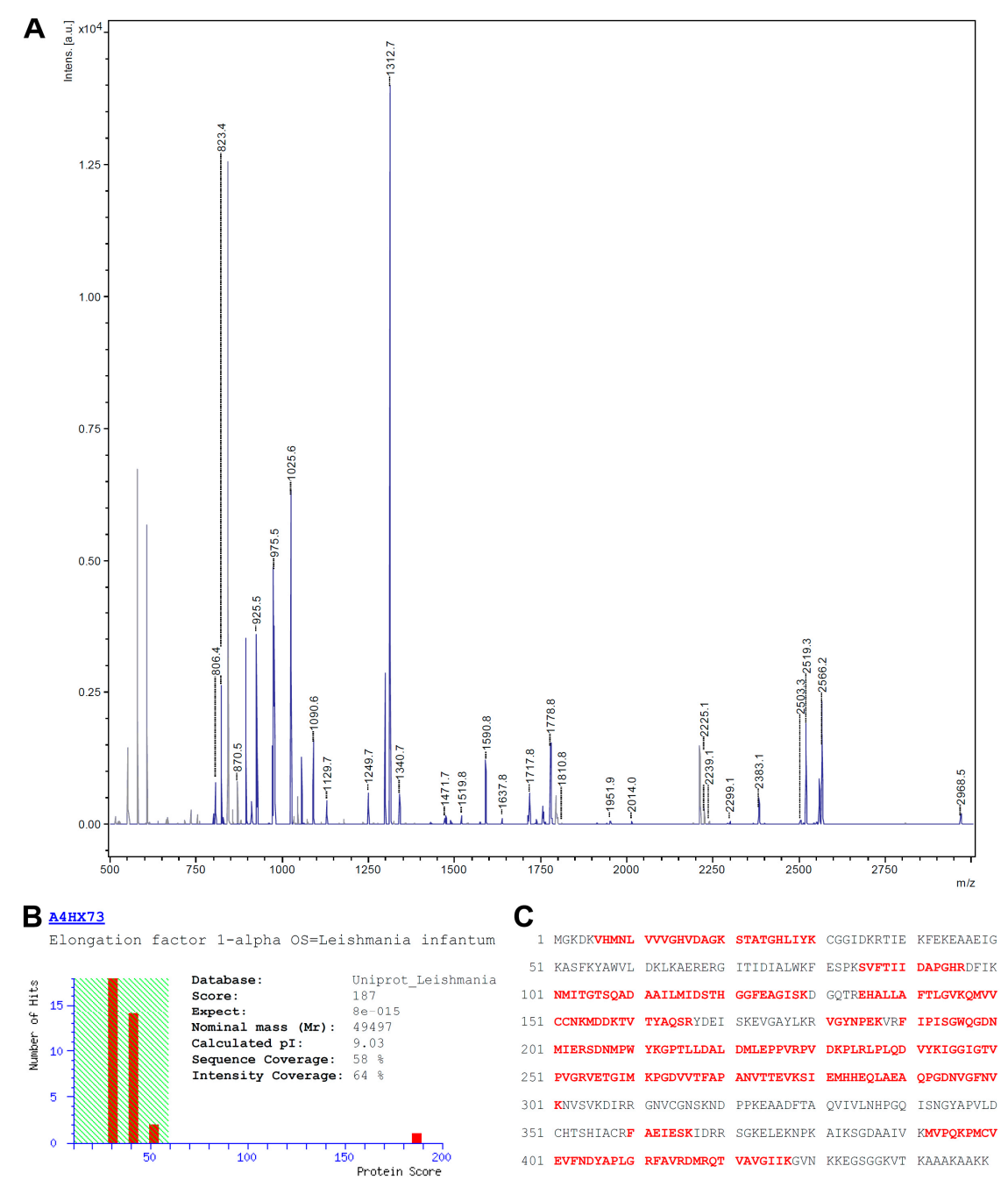

Figure 3. Identification of eEF1 $\alpha$. (A) MS-Spectrum of the tryptic digest of the processed protein spot. Peaks matching to the sequence of eEF1 $\alpha$ are shown in blue; (B) Identification of eEF1 $\alpha$ with a MOWSE score of 187 (scores above 59 are significant; $p<0.05$ ). The theoretical values for the molecular weight and $\mathrm{pI}$ correspond to the observed ones; (C) Sequence of eEF1 $\alpha$ with peptides identified by database search highlighted in red. 


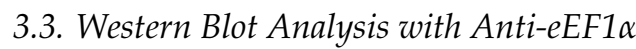

To confirm that the PC-positive spot in the 2D-gel is really eEF1 $\alpha$, a Western blot experiment was performed using an eEF1 $\alpha$-specific antibody (PA5-17213; Thermo Scientific, Dreieich, Germany). In this experiment we also used L. infantum parasites cultivated for ten days instead of three to see whether we get a different pattern of PC-substitution. ECL detection revealed one dominant spot next to a weaker signal with nearly identical molecular weight exactly corresponding to the TEPC-15-positive signal in a parallel Western blot experiment (see Figure 4A,B). The two spots in the PA5-17213 blot confirmed the assumption that more than one eEF1 $\alpha$ proteoforms are present in the L. infantum promastigotes.

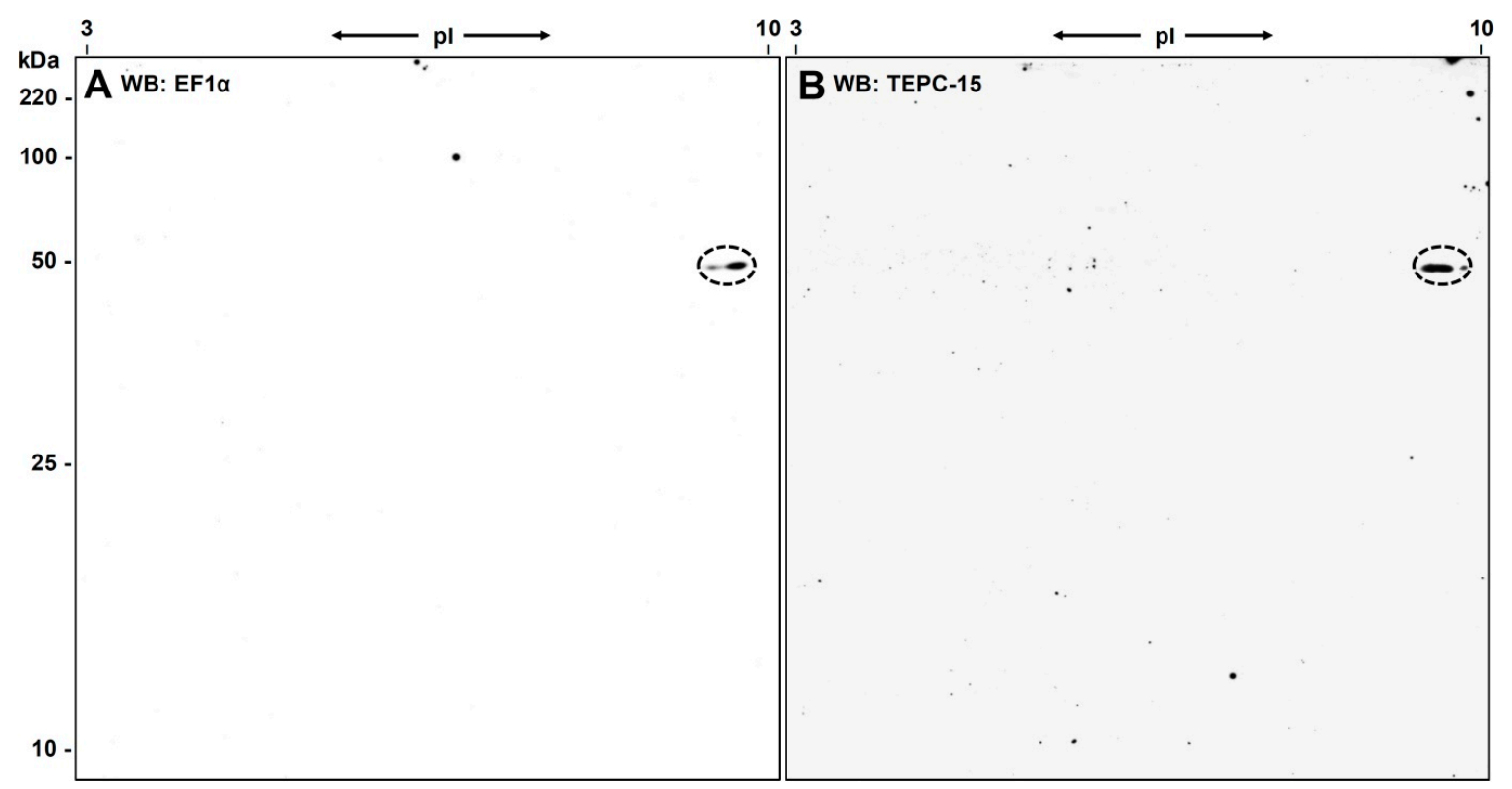

Figure 4. 2D-Western blot analyses with eEF1 $\alpha$ - and PC-specific antibodies. (A) ECL of a Western blot probed with PA5-17213, an eEF1 $\alpha$-specific antibody. The elongation factor is detected at its expected molecular weight $(49.5 \mathrm{kDa})$ but at a slightly higher $\mathrm{pI}$ (9.5 compared to an expected $\mathrm{pI}$ of 9.03$)$. There is also a second spot of the same size but at lower pI detectable, representing another protein species of eEF1 $\alpha(\mathbf{B})$. Both spots of eEF1 $\alpha$ shown in (A) are recognized by the PC-specific antibody TEPC-15. Note that this Leishmania were cultivated for ten days but display no difference in PC-substitution compared to the ones cultivated only for three days.

\subsection{Verification of the Phosphorylcholine Substitution of eEF1 $\alpha$ and Choline Quantitation}

To verify a phosphorylcholine modification of eEF1 $\alpha$, we made use of a HPLC-based method developed by the group of J. Klein [47]. In this method, the retention time of choline was observed on an ion-exchange column. Selective detection of choline was performed with an enzymatic reactor containing immobilized choline oxidase. The amount of choline was measured by the formation of $\mathrm{H}_{2} \mathrm{O}_{2}$, which was then detected electrochemically.

For the analysis of choline, the tryptic peptides from eEF1 $\alpha$ were treated with hydrogene fluoride (HF) which quantitatively cleaves phosphomono- and -diester bonds [49].

For quantitative analysis of the phosphorylcholine substitution, the amount of eEF1 $\alpha$ in the 2D-gel was determined densitometrically by running different amounts of lysozyme, $\beta$-lactoglobulin, aldolase and bovine serum albumin in the second dimension parallel to the sample. After staining the 2D-gel with flamingo, a calibration curve was generated. Starting with $400 \mu \mathrm{g}$ of total protein from L. infantum promastigotes, approx. $1.9 \mu \mathrm{g}$ eEF1 $\alpha$ were found in the PC-positive spots used for choline quantification (see Figure 5). 


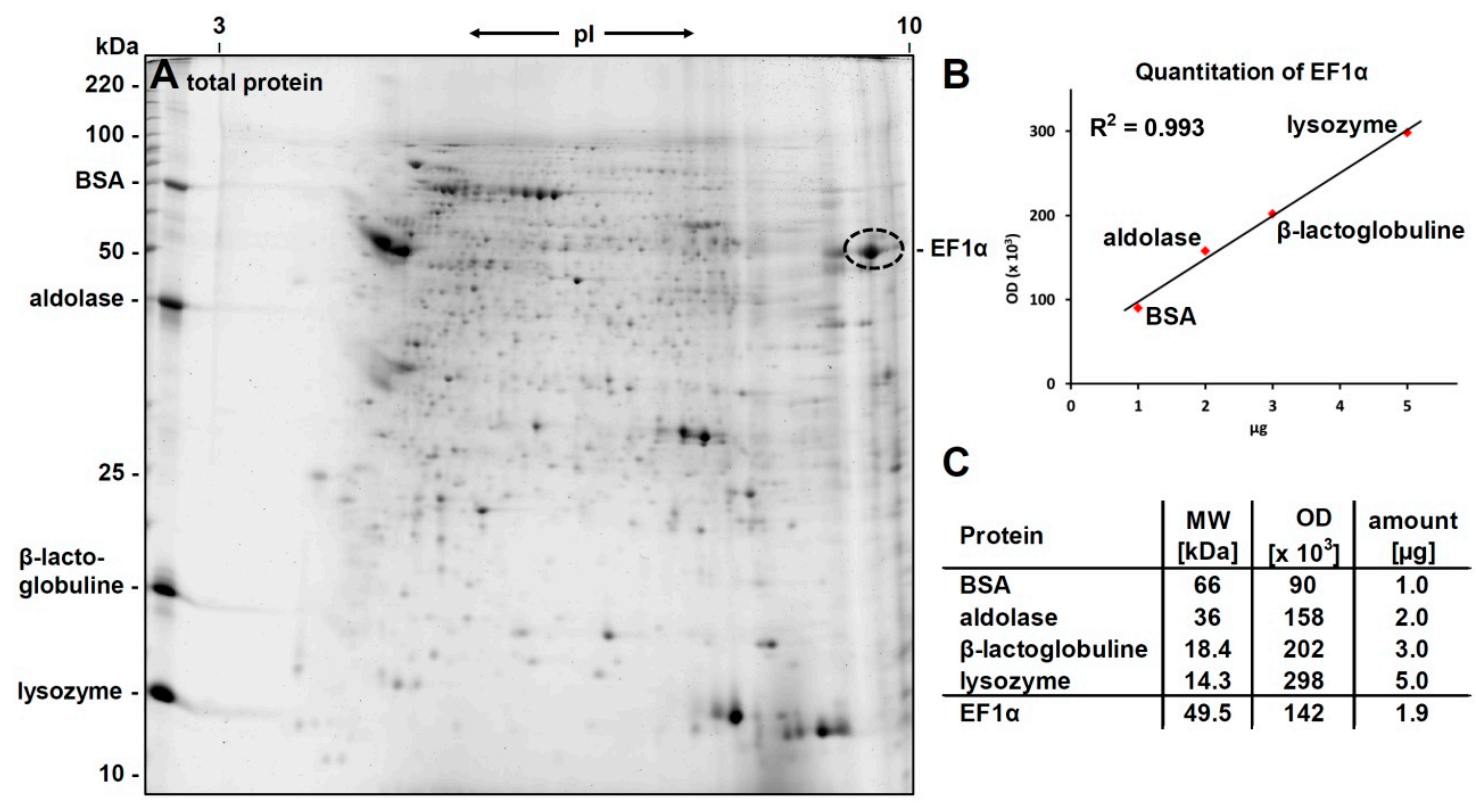

Figure 5. Quantitation of the extracted eEF1 $\alpha$. (A) Gel stained with Flamingo for total protein visualization. To quantify individual spots by densitometric analysis, four proteins with specific amounts were run along the sample in the second dimension; (B) The plot shows the linear correlation of optical densities of the four proteins with their nominal amount; (C) The table displays the data for the calibration proteins and the derived amount of eEF1 $\alpha$ contained in $400 \mu \mathrm{g}$ of total protein extract.

For choline quantitation, tryptic peptides from $310 \mathrm{ng}$ (approx. $6.26 \mathrm{pmol}$ ) eEF1 $\alpha$ were treated with $\mathrm{HF}$ and $1.31 \mathrm{pmol}$ choline were obtained. A repetition of the experiment yielded similar values $(2.1 \mu \mathrm{g}$ EF1 $\alpha$ per $400 \mu \mathrm{g}$ total protein, and $1.32 \mathrm{pmol}$ choline per $7.25 \mathrm{pmol}$ of EF1 $\alpha)$. This indicated a phosphorylcholine substitution degree of around $20 \%$ for eEF1 $\alpha(19.6 \% \pm 1.4 \%)$.

\subsection{Immunohistological Localization of PC Epitopes in L. infantum Promastigotes by Confocal Microscopy}

For immunohistological localization, L. infantum promastigotes were permeabilized with TritonX-100 and fixed on polylysine-coated slides. Again, the PC-specific antibody TEPC-15 was used as primary antibody and a FITC-conjugated secondary antibody was used for immunofluorescence-based localization of the PC epitopes. Additionally, the nuclei and kinetoplasts were stained with DAPI.

The PC epitopes were found to be restricted in the perinuclear region in promastigotes cultured for three days. No other organelles like the kinetoplasts or the flagella were found to carry these epitopes (see Figure 6). Interestingly, the PC epitopes showed a regular pearly distribution around the nucleus (see Figure 6B). As a control, cells were incubated only with the secondary antibody giving no signal (data not shown). However, in Leishmania that where cultivated for ten days the distribution of the PC epitope differed; now the PC-epitope was also found in the whole cytoplasm (Figure 6D,E). 
A
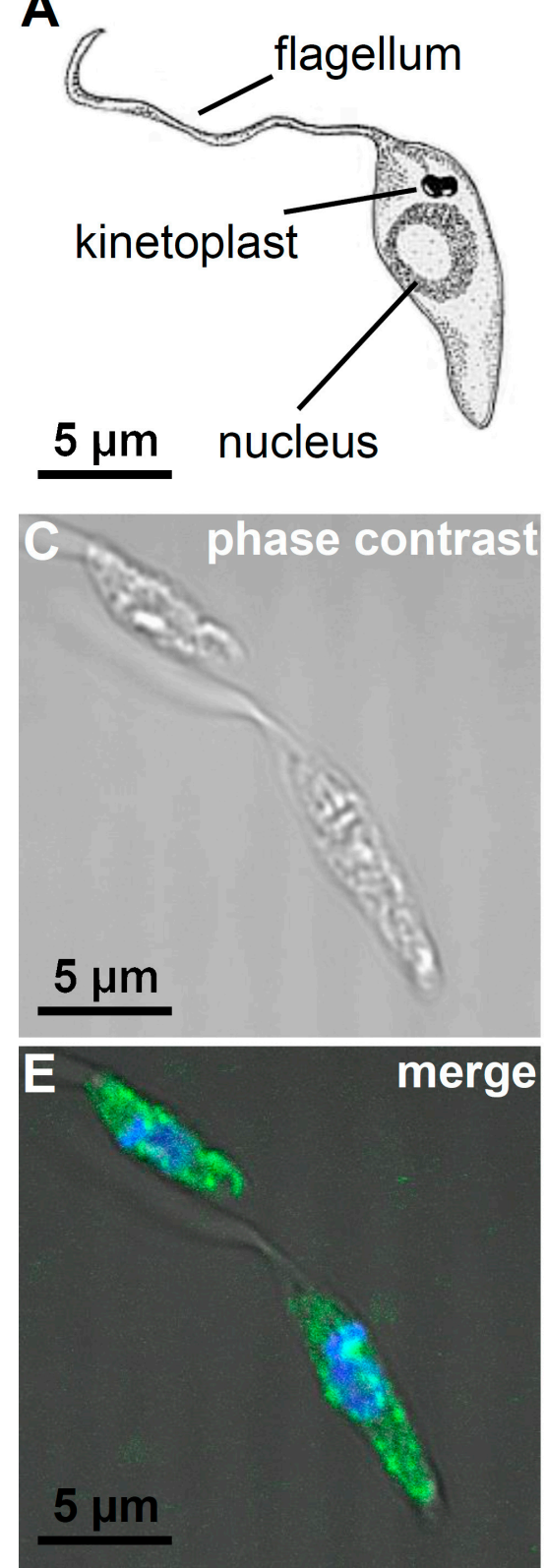
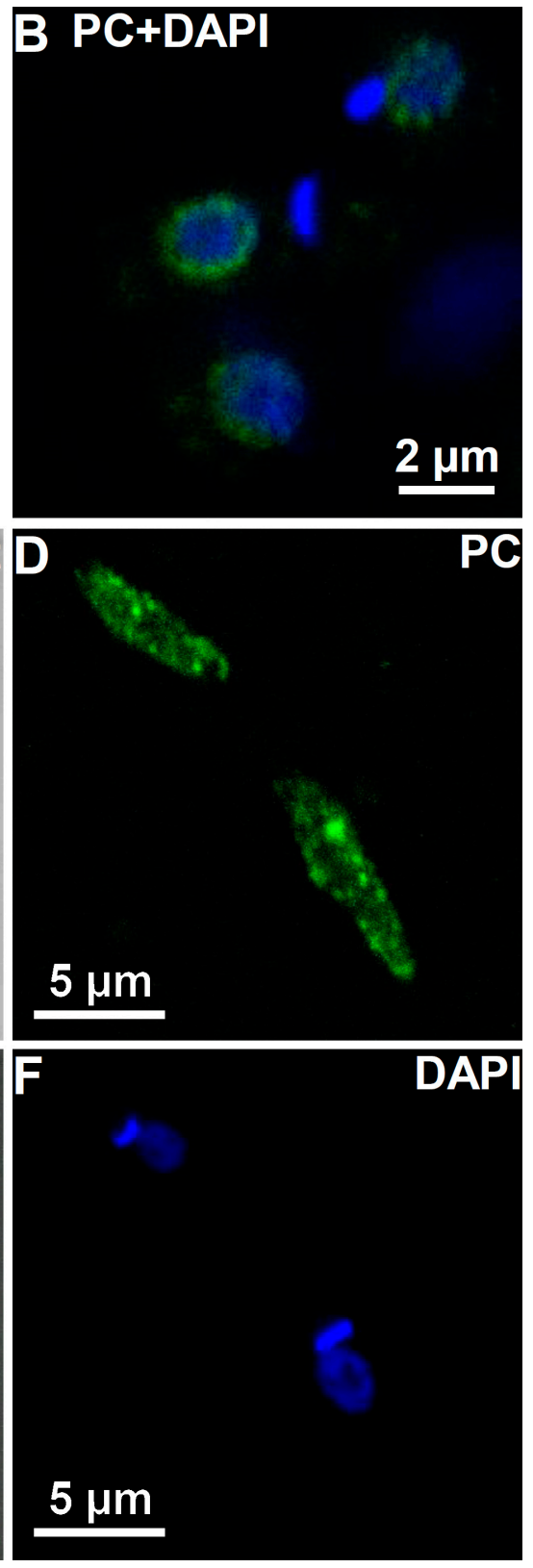

Figure 6. Localization of the PC epitope by confocal microscopy in L. infantum promastigotes. (A) Drawing of a L. infantum promastigote (modified from valleyveterinarygroup.com); (B) Confocal image of three L. infantum promastigotes after three days in culture. The nucleus and the kinetoplast are stained with DAPI (shown in blue). The PC epitope is recognized by the TEPC-15 antibody as a pearly ring around the nucleus (shown in green); (C-F) Confocal images of two L. infantum promastigotes after ten days in culture. The PC epitope is now localized throughout the whole cytoplasm (D); still having a rather dotted and non-homogeneous appearance; Image (E) shows a merge of the phase contrast image (C) with the PC- (D) and DAPI stain (F).

To exclude the possibility that with longer cultivation additional proteins became modified with PC, we extracted L. infantum promastigotes cultured for ten days, performed a 2D-gel separation of the proteins and confirmed in a Western blot analysis with TEPC-15 that still only eEF1 $\alpha$ was detected as PC-modified protein (see Figure 4). 


\subsection{Molecular Function of the PC Modification of EF1 $\alpha$}

In 2012, Silverman and Reiner reported that elongation factor 1 alpha, among other proteins, was delivered into host macrophages via exosomes [45]. In previous work, the same group describes that Leishmania EF-1 $\alpha$ specifically activates the Src homology-2 domain-containing phosphatase-1 (SHP-1), but recombinant protein lacks that function [41]. So we were interested in finding out if the interaction of EF-1 $\alpha$ with SHP-1, which leads to its activation, is influenced by the PC modification of EF- $1 \alpha$. To address this question, we incubated GST-tagged human SHP-1 with a crude extract of L. infantum in presence or absence of $5 \mathrm{mM}$ free phosphorylcholine. SHP-1 and its potential binding partners were then captured utilizing its tag and analyzed by Western blotting. As shown in Figure 7, EF1 $\alpha$ is co-purifying with GST-SHP-1 as expected, but more importantly, this interaction is strongly reduced when PC is included in the extract. This supports the hypothesis that the binding of EF- $1 \alpha$ to SHP-1 is dependent on the modification of EF1 $\alpha$ with PC. In addition, this confirms that EF1 $\alpha$ is really the PC-modified protein and that we were not misled by a molecule co-migrating with the elongation factor in 2D-Gel analysis.

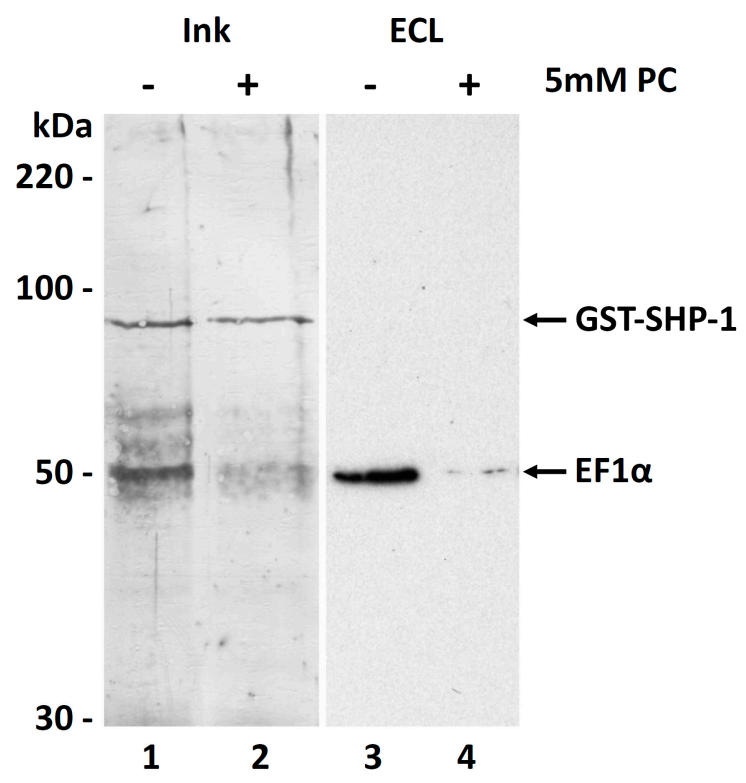

Figure 7. Interaction of L. infantum EF1 $\alpha$ with human SHP-1. Leishmania EF1 $\alpha$ co-purifies with human GST-SHP-1 as detected in a Western blot by the eEF1 $\alpha$-specific antibody (lane 3 ). This interaction is almost completely abolished in presence of $5 \mathrm{mM}$ phosphorylcholine (lane 4). Lanes 1 and 2 show an Ink-staining of the proteins co-eluting with the GST-tagged phosphatase SHP-1 directly on the PVDF membrane. Whereas the SHP-1 ( 90 kDa) is visible in both lanes at similar amounts, a band corresponding to $\mathrm{EF} 1 \alpha(\sim 50 \mathrm{kDa})$ is much stronger in lane 1 than in lane 2, were PC interrupts their interaction.

\section{Discussion}

In this study, we detected a single PC-substituted protein in L. infantum promastigotes, which was definitely identified as eEF1 $\alpha$. eEF1 $\alpha$ represents about $0.5 \%$ of the parasite's total protein extract. The substitution of eEF1 $\alpha$ with the immunomodulatory substituent PC was confirmed by choline quantification to a degree of at least $20 \%$. By confocal microscopy, the PC epitope was found to be localized with a pearly distribution in the perinuclear region in shortly cultivated parasites, whereas after longer cultivation the PC-modified protein is found in the whole cytoplasm. By this, the parasite probably prepares the secretion of the PC-modified elongation factor as reported by Silverman and Reiner [45]. After release into the host cell, this particular modification may be involved in the regulation of the binding of EF1 $\alpha$ to its effector SHP-1. 


\subsection{PC as An Immunomodulatory Substituent}

To escape the immune response, parasites have developed various strategies: the more passive strategies comprise intracellular localization, molecular camouflage by decoration with host-derived molecules or mimicry by synthesizing epitope structures resembling host molecules. More active strategies include the release of compounds degrading immune protective molecules of the host or leading to an immunomodulation of the host's immune response [50].

PC has been recognized as a widespread antigenic determinant in many important disease-causing pathogens, comprising bacteria [51], nematodes [8] and also protozoa belonging to the genera Trypanosoma and Leishmania [9].

The PC modification of biomolecules in pathogens fulfills various functions for the organisms. For nematodes, it could be shown that the modification is important for development and fertility [20]. Bacteria use PC modifications for better adherence to epithelia by binding to the PAF receptor [52]. However, the most important function during infection is the modulation of the host's immune system by PC modifications to escape the immune response.

PC-bearing antigens have been found to possess immunomodulatory capacity and to interfere with key proliferative signaling pathways in B- and T-cells, dendritic cell maturation and mast cell degranulation, thus facilitating the survival of parasites within their hosts $[8,10-17]$.

Detailed data on the different types of PC-carrying compounds as well as their biosynthesis, however, are limited and have only been reported in the last few years [8,18-21].

So far, most PC epitopes investigated revealed glycan-bound PC-moieties. In multicellular parasites, PC has been found on $N$-glycans [21,35] and glycosphingolipids [53]. Additionally, in bacteria, PC was also found on lipopolysaccharide molecules e.g., in Haemophilus influenzae [54-60]. Furthermore, there is evidence for direct modification of amino acids as reported for the Rab1 protein at $\mathrm{Ser}^{76}$ by Legionella pneumophila [61]. However, there is indication that PC might be also bound directly to the protein backbone [62,63]. In eF1 $\alpha$ from L. infantum, we found no evidence for glycosylation. This confirms our observations from its homologue in A. suum: here too, the PC seems to be directly coupled to the sidechains of amino acids [47].

Our proteomic study of L. infantum promastigotes revealed the presence of two spots containing eEF1 $\alpha$ with similar pIs and molecular weights [64]. The ellipsoid form of the PC-positive spot in our study (see Figure 1B) and the two distinct spots in the Western blot using the anti-eEF1 $\alpha$ antibody (see Figure 3A) confirmed these findings. Obviously, both protein species of eEF1 $\alpha$ in these spots carry the PC modification (see Figure 3B). This raises the possibility that the protein might carry additional post-translational modifications. We and others [65] have found no indication for glycosylation; however, a tyrosine phosphorylation of eEF1 $\alpha$ is reported for L. donovani [65].

The biosynthesis of the PC modifications still exhibits open questions since at least for non-bacterial pathogens neither the respective PC-transferase nor the PC-donor could be identified so far [66]. For C. elegans, some putative PC transferases have been postulated [67] by sequence homology to the PC transferase licD from $H$. influenza but they still await confirmation. For the same organism, a PC transferase activity was reported in microsomal preparations indicating phosphatidylcholine as a potential donor for the PC residues [18]. Since only eEF1 $\alpha$ was found to be PC-positive, a quite specific transferase reaction might be postulated for L. infantum. Again, this transferase might be an interesting target for therapeutic intervention to treat Leishmania infections.

\subsection{The Role of $i E F 1 \alpha$ in Parasitism}

The eukaryotic elongation factor 1 alpha $(\mathrm{eEF} 1 \alpha)$ is a housekeeping enzyme that catalyzes the GTP-dependent binding of aminoacyl-tRNA to the A-site of ribosomes during protein synthesis and is involved in the capture of deacylated tRNA [41,42]. The localization to the nucleus led to the suggestion that it may regulate transcription [68]. Furthermore, eEF1 $\alpha$ was found to serve as a central hub in protein networks with hundreds of interacting partners [43,44]. eEF1 $\alpha$ mRNA and protein levels are up-regulated in the stationary phase compared to the logarithmic phase of promastigotes [69]. 
eEF1 $\alpha$ can be considered as a virulence factor in leishmaniasis. Leishmania eEF1 $\alpha$ but not host derived eEF1 $\alpha$ was found to bind and activate the Src-homology 2 domain containing protein tyrosine phosphatase-1 (SHP-1). SHP-1 is then involved in the pathogenesis of Leishmania infection through macrophage inactivation [41] resulting in the progression of leishmaniasis. Additionally, eEF1 $\alpha$ blocks the induction of iNOS in response to interferon- $\gamma$.

The activation of SHP-1 by eEF1 $\alpha$ resembles the up-regulation of SHP-1 by ES-62 in B-cells [70] both being dependent on the PC modification of the respective protein. On the intracellular level, ES-62 selectively targets multiple key signalling pathways following B-cell receptor ligation. By induction of the tyrosine phosphatase SHP-1, which dephosphorylates immuno-receptor tyrosine-based activator motifs (ITAMs), ES-62 prevents recruitment of the Ras/Erk MAP kinase cascade [70,71]. Moreover, recruitment of GAP and the dual phosphatase Pac-1 terminates coupling of B-cell receptor (BCR) signalling to Ras and Erk. ES-62 also negatively modulates the activation of the MAP kinase subfamilies, p38 and c-Jun N-terminal kinase (JNK) [72]. In addition, ES-62 selectively modulates the expression and activity of certain protein kinase C (PKC) isoforms [71,73].

eEF1 $\alpha$ was found in early infection in Leishmania exosomes and identified as an important factor for immunosuppression and priming the host cells for Leishmania invasion [41,45]. These exosomes may suppress TNF- $\alpha$ production of infected monocytes but enhance production of the anti-inflammatory cytokine IL-10. Again, this resembles the biological PC-dependent activity of the immunomodulatory compound ES-62 from the nematode A. viteae.

In summary, these results provide new data for better understanding the biological function of eEF1a as a virulence factor in leishmaniasis.

Acknowledgments: The authors thank Michael Dreisbach, Christina Schmidt and Hans-Günter Welker for excellent technical assistance. The support of Melanie Meister (Institute of Biochemistry) and Christian Zimmermann (Department of Pediatrics) for confocal microscopy is greatly acknowledged. Domenico Otranto is greatly acknowledged for his support.

Author Contributions: Thomas Timm, Giada Annoscia and Guenter Lochnit designed the project. Thomas Timm, Giada Annoscia and Jochen Klein perfomed the experiments. Thomas Timm, Giada Annoscia and Guenter Lochnit wrote the manuscript.

Conflicts of Interest: The authors declare no potential conflicts of interest.

\section{References}

1. Beverley, S.M.; Turco, S.J. Lipophosphoglycan (LPG) and the identification of virulence genes in the protozoan parasite Leishmania. Trends Microbiol. 1998, 6, 35-40. [CrossRef]

2. Kaye, P.M.; Aebischer, T. Visceral leishmaniasis: Immunology and prospects for a vaccine. Clin. Microbiol. Infect. 2011, 17, 1462-1470. [CrossRef] [PubMed]

3. Petersen, C.A.; Barr, S.C. Canine leishmaniasis in North America: Emerging or newly recognized? Vet. Clin. N. Am. Small Anim. Pract. 2009, 39, 1065-1074. [CrossRef] [PubMed]

4. Maroli, M.; Rossi, L.; Baldelli, R.; Capelli, G.; Ferroglio, E.; Genchi, C.; Gramiccia, M.; Mortarino, M.; Pietrobelli, M.; Gradoni, L. The northward spread of leishmaniasis in Italy: Evidence from retrospective and ongoing studies on the canine reservoir and phlebotomine vectors. Trop. Med. Int. Health 2008, 13, $256-264$. [CrossRef] [PubMed]

5. Otranto, D.; Capelli, G.; Genchi, C. Changing distribution patterns of canine vector borne diseases in Italy: Leishmaniosis vs. dirofilariosis. Parasites Vectors 2009, 2 (Suppl. 1), S2. [CrossRef] [PubMed]

6. Dujardin, J.C. Risk factors in the spread of leishmaniases: Towards integrated monitoring? Trends Parasitol. 2006, 22, 4-6. [CrossRef] [PubMed]

7. Seridi, N.; Belkaid, M.; Quispe-Tintaya, W.; Zidane, C.; Dujardin, J.C. Application of PCR-RFLP for the exploration of the molecular diversity of Leishmania infantum in Algeria. Trans. R. Soc. Trop. Med. Hyg. 2008, 102, 556-563. [CrossRef] [PubMed]

8. Lochnit, G.; Dennis, R.D.; Geyer, R. Phosphorylcholine substituents in nematodes: Structures, occurrence and biological implications. Biol. Chem. Hoppe Seyler 2000, 381, 839-847. [CrossRef] [PubMed] 
9. Lal, R.B.; Ottesen, E.A. Phosphocholine epitopes on helminth and protozoal parasites and their presence in the circulation of infected human patients. Trans. R. Soc. Trop. Med. Hyg. 1989, 83, 652-655. [CrossRef]

10. Deehan, M.R.; Goodridge, H.S.; Blair, D.; Lochnit, G.; Dennis, R.D.; Geyer, R.; Harnett, M.M.; Harnett, W. Immunomodulatory properties of Ascaris suum glycosphingolipids-Phosphorylcholine and non-phosphorycholine-Dependent effects. Parasite Immunol. 2002, 24, 463-469. [CrossRef] [PubMed]

11. Harnett, W.; Harnett, M.M. Modulation of the host immune system by phosphorylcholine-containing glycoproteins secreted by parasitic filarial nematodes. Biochim. Biophys. Acta 2001, 1539, 7-15. [CrossRef]

12. Harnett, W.; Harnett, M.M. Phosphorylcholine: Friend or foe of the immune system? Immunol. Today 1999, 20, 125-129. [CrossRef]

13. Harnett, W.; McInnes, I.B.; Harnett, M.M. ES-62, a filarial nematode-derived immunomodulator with anti-inflammatory potential. Immunol. Lett. 2004, 94, 27-33. [CrossRef] [PubMed]

14. Goodridge, H.S.; Harnett, W.; Liew, F.Y.; Harnett, M.M. Differential regulation of interleukin-12 p40 and p35 induction via Erk mitogen-activated protein kinase-dependent and -independent mechanisms and the implications for bioactive IL-12 and IL-23 responses. Immunology 2003, 109, 415-425. [CrossRef] [PubMed]

15. Marshall, F.A.; Grierson, A.M.; Garside, P.; Harnett, W.; Harnett, M.M. ES-62, an immunomodulator secreted by filarial nematodes, suppresses clonal expansion and modifies effector function of heterologous antigen-specific T cells in vivo. J Immunol. 2005, 175, 5817-5826. [CrossRef] [PubMed]

16. Goodridge, H.S.; Marshall, F.A.; Wilson, E.H.; Houston, K.M.; Liew, F.Y.; Harnett, M.M.; Harnett, W. In vivo exposure of murine dendritic cell and macrophage bone marrow progenitors to the phosphorylcholine-containing filarial nematode glycoprotein ES-62 polarizes their differentiation to an anti-inflammatory phenotype. Immunology 2004, 113, 491-498. [CrossRef] [PubMed]

17. Melendez, A.J.; Harnett, M.M.; Pushparaj, P.N.; Wong, W.F.; Tay, H.K.; McSharry, C.P.; Harnett, W. Inhibition of FceRI-mediated mast cell responses by ES-62, a product of parasitic filarial nematodes. Nat. Med. 2007, 13, 1375-1381. [CrossRef] [PubMed]

18. Cipollo, J.F.; Awad, A.; Costello, C.E.; Robbins, P.W.; Hirschberg, C.B. Biosynthesis in vitro of Caenorhabditis elegans phosphorylcholine oligosaccharides. Proc. Natl. Acad. Sci. USA 2004, 101, 3404-3408. [CrossRef] [PubMed]

19. Cipollo, J.F.; Awad, A.M.; Costello, C.E.; Hirschberg, C.B. N-glycans of Caenorhabditis elegans are specific to developmental stages. J. Biol. Chem. 2005, 280, 26063-26072. [CrossRef] [PubMed]

20. Lochnit, G.; Bongaarts, R.; Geyer, R. Searching new targets for anthelminthic strategies: Interference with glycosphingolipid biosynthesis and phosphorylcholine metabolism affects development of Caenorhabditis elegans. Int. J. Parasitol. 2005, 35, 911-923. [CrossRef] [PubMed]

21. Pöltl, G.; Kerner, D.; Paschinger, K.; Wilson, I.B. N-Glycans of the porcine nematode parasite Ascaris suum are modified with phosphorylcholine and core fucose residues. FEBS J. 2007, 274, 714-726. [CrossRef] [PubMed]

22. Lochnit, G.; Dennis, R.D.; Ulmer, A.J.; Geyer, R. Structural elucidation and monokine-inducing activity of two biologically active zwitterionic glycosphingolipids derived from the porcine parasitic nematode Ascaris suum. J. Biol. Chem. 1998, 278, 466-474. [CrossRef]

23. Griffitts, J.S.; Haslam, S.M.; Yang, T.; Garczynski, S.F.; Mulloy, B.; Morris, H.; Cremer, P.S.; Dell, A.; Adang, M.J.; Aroian, R.V. Glycolipids as receptors for Bacillus thuringiensis crystal toxin. Science 2005, 307, 922-925. [CrossRef] [PubMed]

24. Friedl, C.H.; Lochnit, G.; Zähringer, U.; Bahr, U.; Geyer, R. Structural elucidation of zwitterionic carbohydrates derived from glycosphingolipids of the porcine parasitic nematode Ascaris suum. Biochem. J. 2003, 369, 89-102. [CrossRef] [PubMed]

25. Dennis, R.D.; Baumeister, S.; Smuda, C.; Lochnit, G.; Waider, T.; Geyer, E. Initiation of chemical studies on the immunoreactive glycolipids of adult Ascaris suum. Parasitology 1995, 110, 611-623. [CrossRef] [PubMed]

26. Baumeister, S.; Dennis, R.D.; Klünder, R.; Schares, G.; Zahner, H.; Geyer, E. Litomosoides carinii: Macrofilariae-derived glycolipids-Chromatography, serology and potential in the evaluation of anthelminthic efficacy. Parasite Immunol. 1994, 16, 629-641. [CrossRef] [PubMed]

27. Wuhrer, M.; Rickhoff, S.; Dennis, R.D.; Lochnit, G.; Soboslay, P.T.; Baumeister, S.; Geyer, R. Phosphocholine-containing, zwitterionic glycosphingolipids of adult Onchocerca volvulus as highly conserved, antigenic structures of parasitic nematodes. Biochem. J. 2000, 348, 417-423. [CrossRef] [PubMed] 
28. Gerdt, S.; Lochnit, G.; Dennis, R.D.; Geyer, R. Isolation and structural analysis of three neutral glycosphingolipids from a mixed population of Caenorhabditis elegans (Nematoda: Rhabditida). Glycobiology 1997, 7, 265-275. [CrossRef] [PubMed]

29. Gerdt, S.; Dennis, R.D.; Borgonie, G.; Schnabel, R.; Geyer, R. Isolation, characterization and immunolocalization of phosphocholine-substituted glycolipids in developmental stages of Caenorhabditis elegans. Eur. J. Biochem. 1999, 266, 952-963. [CrossRef] [PubMed]

30. Harnett, W.; Houston, K.M.; Amess, R.; Worms, M.J. Acanthocheilonema viteae: Phosphorylcholine is attached to the major excretory-secretory product via an $N$-linked glycan. Exp. Parasitol. 1993, 77, 498-502. [CrossRef] [PubMed]

31. Harnett, W.; Frame, M.J.; Nor, Z.M.; MacDonald, M.; Houston, K.M. Some preliminary data on the nature/structure of the PC-glycan of the major excretory-secretory product of Acanthocheilonema viteae (ES-62). Parasite 1994, 1, 179-181. [CrossRef] [PubMed]

32. Haslam, S.M.; Khoo, K.H.; Houston, K.M.; Harnett, W.; Morris, H.R.; Dell, A. Characterisation of the phosphorylcholine-containing $N$-linked oligosaccharides in the excretory-secretory $62 \mathrm{kDa}$ glycoprotein of Acanthocheilonema viteae. Mol. Biochem. Parasitol. 1997, 85, 53-66. [CrossRef]

33. Haslam, S.M.; Gems, D.; Morris, H.R.; Dell, A. The glycomes of Caenorhabditis elegans and other model organisms. Biochem. Soc. Symp. 2002, 69, 117-134. [CrossRef]

34. Haslam, S.M.; Dell, A. Hallmarks of Caenorhabditis elegans N-glycosylation: Complexity and controversy. Biochimie 2003, 85, 25-32. [CrossRef]

35. Haslam, S.M.; Houston, K.M.; Harnett, W.; Reason, A.J.; Morris, H.R.; Dell, A. Structural studies of N-glycans of filarial parasites. Conservation of phosphorylcholine-substituted glycans among species and discovery of novel chito-oligomers. J. Biol. Chem. 1999, 274, 20953-20960. [CrossRef] [PubMed]

36. Cipollo, J.F.; Costello, C.E.; Hirschberg, C.B. The fine structure of Caenorhabditis elegans N-glycans. J. Biol. Chem. 2002, 277, 49143-49157. [CrossRef] [PubMed]

37. Grabitzki, J.; Lochnit, G. Immunomodulation by phosphocholine-Biosynthesis, structures and immunological implications of parasitic PC-epitopes. Mol. Immunol. 2009, 47, 149-163. [CrossRef] [PubMed]

38. Trimnell, A.R.; Kraemer, S.M.; Mukherjee, S.; Phippard, D.J.; Janes, J.H.; Flamoe, E.; Su, X.Z.; Awadalla, P.; Smith, J.D. Global genetic diversity and evolution of var genes associated with placental and severe childhood malaria. Mol. Biochem. Parasitol. 2006, 148, 169-180. [CrossRef] [PubMed]

39. Chen, Q.; Fernandez, V.; Sundstrom, A.; Schlichtherle, M.; Datta, S.; Hagblom, P.; Wahlgren, M. Developmental selection of var gene expression in Plasmodium falciparum. Nature 1998, 394, 392-395. [CrossRef] [PubMed]

40. Shonhai, A.; Boshoff, A.; Blatch, G.L. The structural and functional diversity of Hsp70 proteins from Plasmodium falciparum. Protein Sci. 2007, 16, 1803-1818. [CrossRef] [PubMed]

41. Nandan, D.; Yi, T.; Lopez, M.; Lai, C.; Reiner, N.E. Leishmania EF-1alpha activates the Src homology 2 domain containing tyrosine phosphatase SHP-1 leading to macrophage deactivation. J. Biol. Chem. 2002, 277, 50190-50197. [CrossRef] [PubMed]

42. Negrutskii, B.S.; El'skaya, A.V. Eukaryotic translation elongation factor 1 alpha: Structure, expression, functions, and possible role in aminoacyl-tRNA channeling. Prog. Nucleic Acid Res. Mol. Biol. 1998, 60, 47-78. [PubMed]

43. Gavin, A.C.; Aloy, P.; Grandi, P.; Krause, R.; Boesche, M.; Marzioch, M.; Rau, C.; Jensen, L.J.; Bastuck, S.; Dümpelfeld, B.; et al. Proteome survey reveals modularity of the yeast cell machinery. Nature 2006, 440, 631-636. [CrossRef] [PubMed]

44. Hermjakob, H.; Montecchi-Palazzi, L.; Lewington, C.; Mudali, S.; Kerrien, S.; Orchard, S.; Vingron, M.; Roechert, B.; Roepstorff, P.; Valencia, A.; et al. IntAct: An open source molecular interaction database. Nucleic Acids Res. 2004, 32, D452-D455. [CrossRef] [PubMed]

45. Silverman, J.M.; Reiner, N.E. Leishmania exosomes deliver preemptive strikes to create an environment permissive for early infection. Front. Cell. Infect. Microbiol. 2012, 1, 26. [CrossRef] [PubMed]

46. Evans, D.A. Leishmania: In Vitro Methods for Parasite Cultivation; Taylor, A.E., Baker, J.R., Eds.; Academic Press: Orlando, FL, USA, 1987; pp. 52-75. 
47. Timm, T.; Grabitzki, J.; Severcan, C.; Muratoglu, S.; Ewald, L.; Yilmaz, Y.; Lochnit, G. The PCome of Ascaris suum as a model system for intestinal nematodes: Identification of phosphorylcholine-substituted proteins and first characterization of the PC-epitope structures. Parasitol. Res. 2016, 115, 1263-1274. [CrossRef] [PubMed]

48. Mohr, F.; Zimmermann, M.; Klein, J. Mice heterozygous for AChE are more sensitive to AChE inhibitors but do not respond to BuChE inhibition. Neuropharmacology 2013, 67, 37-45. [CrossRef] [PubMed]

49. Dennis, R.D.; Lochnit, G.; Geyer, R. Strategies for preliminary characterization of novel amphoteric glycosphingolipids. Methods Mol. Biol. 1998, 76, 197-212. [PubMed]

50. Sorci, G.; Cornet, S.; Faivre, B. Immune evasion, immunopathology and the regulation of the immune system. Pathogens 2013, 2, 71-91. [CrossRef] [PubMed]

51. Clark, S.E.; Weiser, J.N. Microbial modulation of host immunity with the small molecule phosphorylcholine. Infect. Immun. 2013, 81, 392-401. [CrossRef] [PubMed]

52. Swords, W.E.; Buscher, B.A.; Ver Steeg Ii, K.; Preston, A.; Nichols, W.A.; Weiser, J.N.; Gibson, B.W.; Apicella, M.A. Non-typeable Haemophilus influenzae adhere to and invade human bronchial epithelial cells via an interaction of lipooligosaccharide with the PAF receptor. Mol. Microbiol. 2000, 37, 13-27. [CrossRef] [PubMed]

53. Lochnit, G.; Nispel, S.; Dennis, R.D.; Geyer, R. Structural analysis and immunohistochemical localization of two acidic glycosphingolipids from the porcine, parasitic nematode, Ascaris suum. Glycobiology 1998, 8, 891-899. [CrossRef] [PubMed]

54. Weiser, J.N.; Pan, N. Adaptation of Haemophilus influenzae to acquire and innate humoral immunity based on phase variation of lipopolysaccharide. Mol. Microbiol. 1998, 30, 767-775. [CrossRef] [PubMed]

55. Risberg, A.; Masoud, H.; Martin, A.; Richards, J.C.; Moxon, E.R.; Schweda, E.K. Structural analysis of the lipopolysaccharide oligosaccharide epitopes expressed by a capsule-deficient strain of Haemophilus influenzae Rd. Eur. J. Biochem. 1999, 261, 171-180. [CrossRef] [PubMed]

56. Schweda, E.K.; Brisson, J.R.; Alvelius, G.; Martin, A.; Weiser, J.N.; Hood, D.W.; Moxon, E.R.; Richards, J.C. Characterization of the phosphocholine-substituted oligosaccharide in lipopolysaccharides of type B Haemophilus influenzae. Eur. J. Biochem. 2000, 267, 3902-3913. [CrossRef] [PubMed]

57. Mansson, M.; Bauer, S.H.; Hood, D.W.; Richards, J.C.; Moxon, E.R.; Schweda, E.K. A new structural type for Haemophilus influenzae lipopolysaccharide. Structural analysis of the lipopolysaccharide from nontypeable Haemophilus influenzae strain 486. Eur. J. Biochem. 2001, 268, 2148-2159. [CrossRef] [PubMed]

58. Mansson, M.; Hood, D.W.; Li, J.; Richards, J.C.; Moxon, E.R.; Schweda, E.K. Structural analysis of the lipopolysaccharide from nontypeable Haemophilus influenzae strain 1003. Eur. J. Biochem. 2002, 269, 808-818. [CrossRef] [PubMed]

59. Fudala, R.; Kondakova, A.N.; Bednarska, K.; Senchenkova, S.N.; Shashkov, A.S.; Knirel, Y.A.; Zähringer, U.; Kaca, W. Structure and serological characterization of the O-antigen of Proteus mirabilis O18 with a phosphocholine-containing oligosaccharide phosphate repeating unit. Carbohydr. Res. 2003, 338, 1835-1842. [CrossRef]

60. Landerholm, M.K.; Li, J.; Richards, J.C.; Hood, D.W.; Moxon, E.R.; Schweda, E.K. Characterization of novel structural features in the lipopolysaccharide of nondisease associated nontypeable Haemophilus influenzae. Eur. J. Biochem. 2004, 271, 941-953. [CrossRef] [PubMed]

61. Tan, Y.; Arnold, R.J.; Luo, Z.Q. Legionella pneumophila regulates the small GTPase Rab1 activity by reversible phosphorylcholination. Proc. Natl. Acad. Sci. USA 2011, 108, 21212-21217. [CrossRef] [PubMed]

62. Lochnit, G.; Grabitzki, J.; Henkel, B.; Tavernarakis, N.; Geyer, R. First identification of a phosphorylcholine-substituted protein from Caenorhabditis elegans. Isolation and characterization of the aspartyl protease ASP-6. Biol. Chem. Hoppe Seyler 2006, 387, 1487-1493. [CrossRef] [PubMed]

63. Lovell, T.M.; Woods, R.J.; Butlin, D.J.; Brayley, K.J.; Manyonda, I.T.; Jarvis, J.; Howell, S.; Lowry, P.J. Identification of a novel mammalian post-translational modification, phosphocholine, on placental secretory polypeptides. J. Mol. Endocrinol. 2007, 39, 189-198. [CrossRef] [PubMed]

64. Alcolea, P.J.; Alonso, A.; Larraga, V. Proteome profiling of Leishmania infantum promastigotes. J. Eukaryot Microbiol. 2011, 58, 352-358. [CrossRef] [PubMed]

65. Nandan, D.; Cherkasov, A.; Sabouti, R.; Yi, T.; Reiner, N.E. Molecular cloning, biochemical and structural analysis of elongation factor-1 alpha from Leishmania donovani: Comparison with the mammalian homologue. Biochem. Biophys. Res. Commun. 2003, 302, 646-652. [CrossRef] 
66. Houston, K.; Lochnit, G.; Geyer, R.; Harnett, W. Investigation of the nature of potential phosphorylcholine donors for filarial nematode glycoconjugates. Mol. Biochem. Parasitol. 2002, 123, 55-66. [CrossRef]

67. Harnett, W.; Rzepecka, J.; Houston, K.M. How do nematodes transfer phosphorylcholine to carbohydrates? Trends Parasitol. 2010, 26, 114-118. [CrossRef] [PubMed]

68. Billaut-Mulot, O.; Fernandez-Gomez, R.; Loyens, M.; Ouaissi, A. Trypanosoma cruzi elongation factor 1-alpha: Nuclear localization in parasites undergoing apoptosis. Gene 1996, 174, 19-26. [CrossRef]

69. Alcolea, P.J.; Alonso, A.; Gomez, M.J.; Moreno, I.; Dominguez, M.; Parro, V.; Larraga, V. Transcriptomics throughout the life cycle of Leishmania infantum: High down-regulation rate in the amastigote stage. Int. J. Parasitol. 2010, 40, 1497-1516. [CrossRef] [PubMed]

70. Deehan, M.R.; Harnett, W.; Harnett, M.M. A filarial nematode-secreted phosphorylcholine-containing glycoprotein uncouples the B cell antigen receptor from extracellular signal-regulated kinase-mitogen-activated protein kinase by promoting the surface ig-mediated recruitment of src homology 2 domain-containing tyrosine phosphatase-1 and pac-1 mitogen-activated kinase-phosphatase. J. Immunol. 2001, 166, 7462-7468. [PubMed]

71. Deehan, M.R.; Harnett, M.M.; Harnett, W. A filarial nematode secreted product differentially modulates expression and activation of protein kinase C isoforms in B lymphocytes. J. Immunol. 1997, 159, 6105-6111. [PubMed]

72. Goodridge, H.S.; Deehan, M.R.; Harnett, W.; Harnett, M.M. Subversion of immunological signalling by a filarial nematode phosphorylcholine-containing secreted product. Cell Signal. 2005, 17, 11-16. [CrossRef] [PubMed]

73. Harnett, W.; Harnett, M.M. Inhibition of murine B cell proliferation and down-regulation of protein kinase $\mathrm{C}$ levels by a phosphorylcholine-containing filarial excretory-secretory product. J. Immunol. 1993, 151, 4829-4837. [PubMed]

Sample Availability: Samples of the compounds are not available from the authors.

(C) 2017 by the authors. Licensee MDPI, Basel, Switzerland. This article is an open access article distributed under the terms and conditions of the Creative Commons Attribution (CC BY) license (http:/ / creativecommons.org/licenses/by/4.0/). 